\title{
Correction to: Personal, relational and school factors associated with involvement in fights with weapons among school-age youth in Brazil: a multilevel ecological approach
}

\author{
Maria Fernanda Tourinho Peres ${ }^{1} \cdot$ Catarina Machado Azeredo $^{2} \cdot$ Leandro Fórnias Machado de Rezende $^{1}$. \\ Eliana Miura Zucchi ${ }^{3} \cdot$ Ivan Franca-Junior $^{4} \cdot$ Olinda do Carmo Luiz $^{1} \cdot$ Renata Bertazzi Levy $^{1}$
}

Published online: 22 August 2018

(C) Swiss School of Public Health (SSPH+) 2018

\section{Correction to: International Journal of Public Health} https://doi.org/10.1007/s00038-018-1128-0

The authors would like to include the funding note here which was found missing in the original publication.

Funding Funding agency for Peres is MFT (Fundação de Amparo àPesquisa do Estado de São Paulo-FAPESPNo. 2015/16142-4). Funding agency for Levy is RB (National Council for Scientific and Technological Development (CNPq) (No. 444794/2014-0)).

Also in the ethics section, CPeNSE should be written as PeNSE.

The original article can be found online at https:// doi.org/10.1007/s00038-018-1128-0.

Maria Fernanda Tourinho Peres

mftperes@usp.br

1 Departamento de Medicina Preventiva, Faculdade de Medicina FMUSP, Universidade de Sao Paulo, Av. Dr. Arnaldo 455, $2^{\circ}$ andar, 01246-903 São Paulo, SP, Brazil

2 Curso de Nutrição, Faculdade de Medicina da, Universidade Federal de Uberlândia, Uberlândia, Minas Gerais 38.405-320, Brazil

3 Programa de Pós-Graduação em Saúde Coletiva, Universidade Católica de Santos, Santos, Brazil

4 School of Public Health, USP, São Paulo, Brazil 